\title{
Patients with Klippel - Trenaunay Syndrome
}

\author{
Zavacká $\mathbf{M}^{* 1}$, Pobehová J ${ }^{1}$ and Zavacký $\mathbf{P}^{2}$ \\ ${ }^{1}$ Clinic of Vascular Surgery, Faculty of Medicine UPJŠ and East Slovak Institute of Cardiovascular Diseases, South korea
}

${ }^{2}$ Surgery Clinic, L. Pasteur University hospital, South Korea

Received: May 12, 2018; Published: May 23, 2018

*Corresponding author: Martina Závacká, Clinic of Vascular Surgery, Faculty of Medicine UPJŠ and East Slovak Institute of Cardiovascular Diseases, Inc., Ondavská 8, 04011 Košice, South Korea

\begin{abstract}
Summary: Klippel-Trenaunay syndrome is the most frequent systemic venous angiodysplasia. It is characterized by cutaneous capillary malformations - naevus flammeus, excessive growth of soft and bone tissue, venous and lymphatic malformations.

Investigative Methods Include: clinical examinations, venography as the evidence of dysplastic changes of superficial and / or deep venous system, the Moyne obstruction and venous insufficiency perforator. Treatment is conservative, related to that of chronic venous disease. The surgery is aimed at removing the varices and insufficient perforators.
\end{abstract}

Keywords: Klippel-Trenaunay syndrome; Varices; Naevus flammeus; Tissue hypertrophy

\section{Introduction}

Klippel and Trenaunay in 1900 described the clinical syndrome with characteristic signs on the lower limb:

a) Varices (formed already in the childhood),

b) Naevus flammeus,

c) Hypertrophy of tissues (especially bones with limb prolongation) [1].

They pointed out the venous angiodysplasia, belonging to the non-degenerative and non-inflammatory angiopathies [2]. Naevus flammeus occurs in all cases. The authors also described cruciate, or dissociated type, where varices and hypertrophy occur on one and naevus on the other limb. Klippel-Trenaunay syndrome is often confused with Parks-Weber syndrome. At the other one, A-V shunt is always present, at which there are palpable whirl, pain, and pulsing veins prone to rapid progression and frequent relapses. Clinically it manifests by vein dilatation and cardiac decompensation $[3,4]$. The syndrome is often connected with malformations of lymphatic blood vessels and lymphoedema; therefore it is favorable to perform an operation in childhood to prevent the onset of big oedema and limb elongation [5].

The syndrome incidence is $1 / 20000-40000$ live-born children. The diagnosis can be made according to the specialist at the Mayo clinic if two of three main symptoms are present. The incidence is sporadic, men and women are affected equally often, the racial predilection was not found, and symptoms may appear at birth, or during childhood [6].

\section{Case History No. 1}

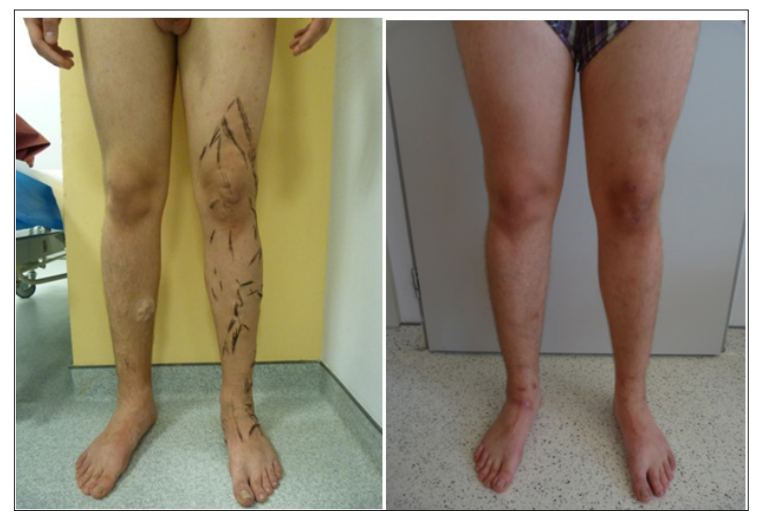

Figure 1: Varicosity on the left lower limb in the patient with TKS (status before operation, and after operation).

20 years old patient was admitted to the Clinic of vascular surgery, East Slovak Institute of Cardiovascular Diseases, Inc. in Košice for the first time in December 2014 for surgical solving of the chronic venous insufficiency on the left lower limb with the presence of pronounced stem varices, concentrated mainly medially on the right shin (Figure 1). At admission the limb oedema was present $+2 \mathrm{~cm}$ in full size. At physical examination we observed on the chest centrally not clearly limited haemangioma of the size of $7 \times 5 \mathrm{~cm}$. (Figure 2). The patient in his history told about exercise-induced redness of the skin in the exposed area, deviation of the nasal septum, and status post operation of $3 \mathrm{rd}$ and $4^{\text {th }}$ finger of the left upper limb for syndactyly (Figure 3). Subsequently, due to suspect- 
ed Klippel - Trenaunay syndrome, the ultrasound and CT AG examinations of the venous system of lower limbs was supplemented.

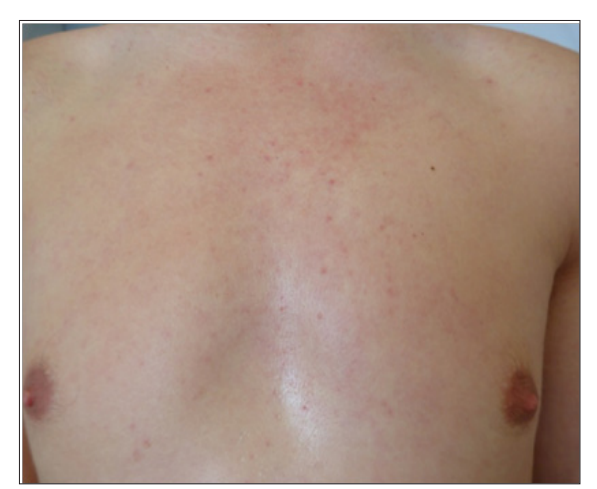

Figure 2: Naevus flammeus localised on the chest.

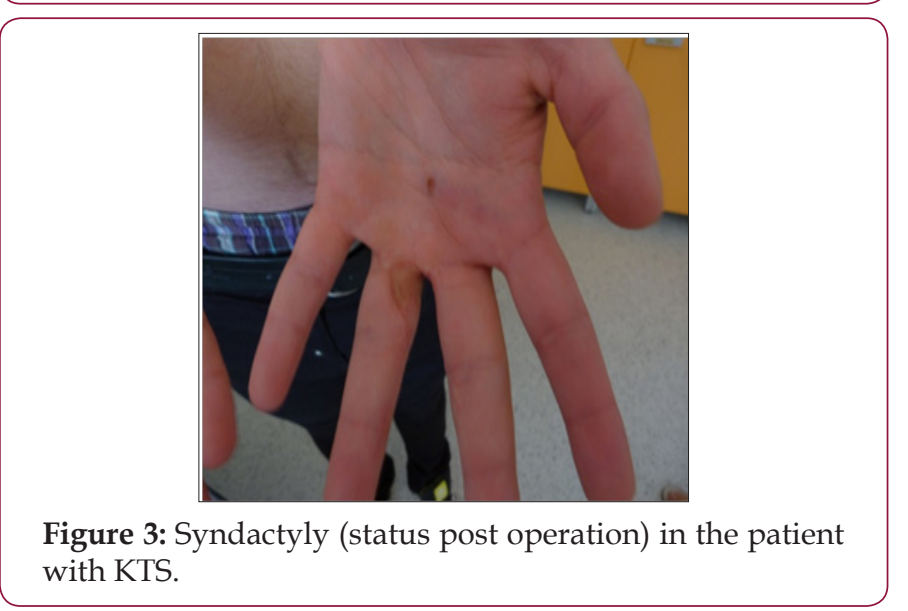

Figure 3: Syndactyly (status post operation) in the patient with KTS.

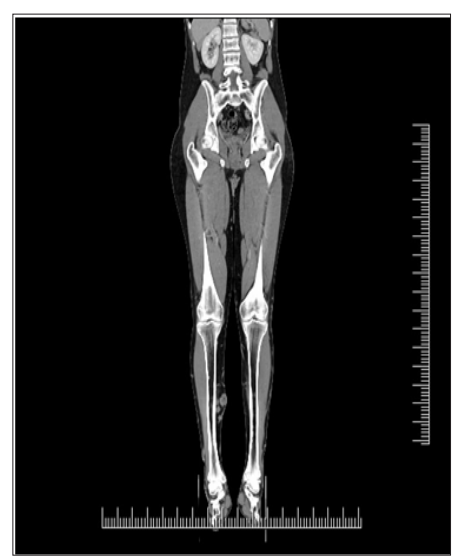

Figure 4: Varicosity of the right tibia in the transversal section.

The CT AG examination shows potential A-V malformation on the lower limb in the anteromedial region of the shin, and varicose focuses throughout the whole tibia (Figure 4). The examination does not confirm any lytic changes of bone structures. The patient was also examined in the respect of haemo-coagulation, and the thrombophilia was confirmed. After diagnostics and preparation, the patient underwent an operation. The stem insufficiency VSM sinl towards to v. accesoria anterior l. sin., confirmed by ultrasound and CT AG findings were the indication for surgery. Subsequently, crossectomia and stripping VSM throughout the whole course, obliterated $v v$. perforantes CI-CIII, posterior gastrocnomic and anterior lateral branch. Post operation the patient was afebrile, pressure and pulse stable and compensated, surgical wounds were calm, did not leak healed p.p.i. The patient was informed on the next treatment procedure (elastic bandage, drinking and motion regimen), and was released to the outdoor care.

After the recovery period in February 2015 he was re-admitted to the Clinic of Vascular Surgery in order to remove SF reflux on the right lower limb, where extensive stem varices were present as well as on the collateral side. In the early post-operative period, there were no complications, so the patient was informed about his health status and the need for the medication, and released for the outpatient care.

\section{Case History No. 2}

39 years old woman patient was admitted to the Clinic of vascular surgery, East Slovak Institute of Cardiovascular Diseases, Inc. in Košice for persistent swelling of the left tibia, progression of relapsing varicose veins of the left tibia with the tendency to deterioration. In anamnesis she overcame usual childhood diseases, surgery of varicose veins in the left lower limb at the catchment surgical department, in the dispensary of angiologist and orthopaedist for spine scoliosis. For a long time she used venotonics and anticoagulant therapy with low molecular heparin (LMWH). Within the family there were no problems with varicose veins. At admission, on the shin on the right there were extensive stem varicosities, pretibial and perimalleolar oedema.

Pulsations were bilaterally well tangible at full range; trophic changes of the skin and adnex were not present. In the sacral region there was haemangioma of the size of $10 \times 10 \mathrm{~cm}$ (Figure 5).

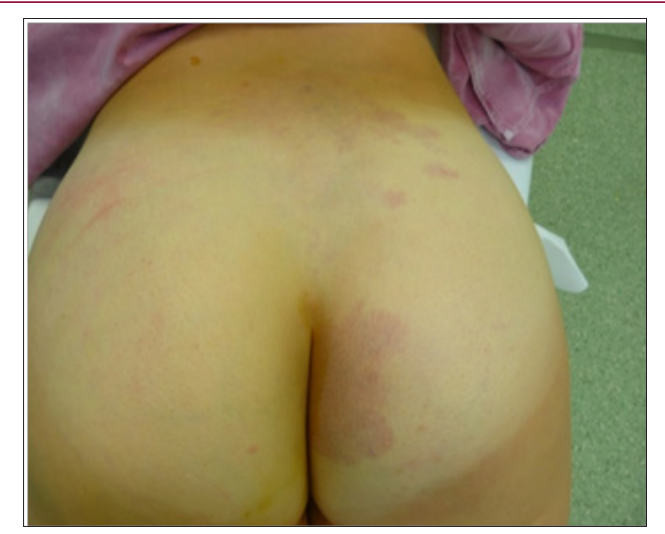

Figure 5: Naevus flammeus in the sacral and right gluteal region.

The whole left lower limb was thicker by $3-4 \mathrm{~cm}$. The left foot was significantly smaller than the right one, with skeletal malformation (Figure 6). In the control ultrasound of the lower limb vein system the finding on the left lower limb was following: v. saphe$n a$ magna as well as $v$. saphena parva were extirpated, without any signs of recurrence, perforators on the tibia were sufficient. On the dorsal side of the thigh the cranial extension protruding from the stump of the extirpated $v$. saphena parva was confirmed by examination. It was significantly dilated with the luminal diameter of 13.5 
$\mathrm{mm}$. Extension was drained by dilated perforator in the middle of dorsomedial side of the thigh running into $v$. femoralis l.sin.

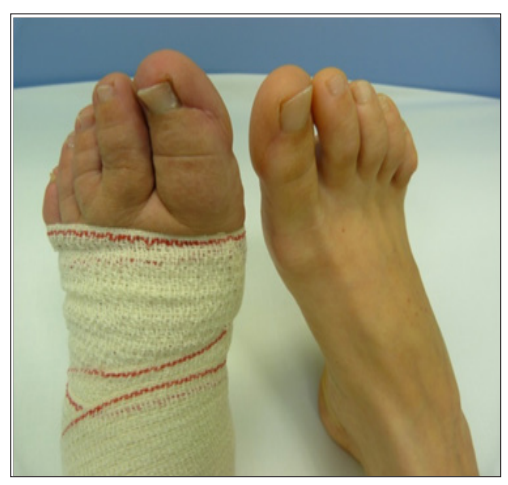

Figure 6: Deformities and changed configuration of the left foot.

In the preoperative examination the normochromatic anaemic syndrome of slight degree v.s. sideropenic, leucopaenia of slight degree, and slight hypercholesterolemia dominated in the laboratory picture. According to the examination conclusion, the patient was cardio-pulmonary compensated without any contraindications to surgery. Under the total anaesthesia in the position on the abdomen, the stump of $v$. saphena parva l.sin was anatomized, its distal and proximal extension. The distal extension was fibrotically changed, probably after previous surgery. The proximal one was about $0.7 \mathrm{~cm}$, fibrotically changed after previous inflammations. After its skeletinization in the middle third of the back half of the thigh we ligated its tertiary part in the confluence into $v$. femoralis l.sin. This eliminated the reflux between the proximal extension of v. saphena parva and $v$. femoralis l.sin. In the post-operative period the patient was a febrile, stabilized, and compensated. Surgical wounds healed p.p.i.

\section{Conclusion}

Klippel-Trenaunay syndrome belongs among the most often occurring venous angiodysplasia. Its incidence is confirmed at least by two of three malformations: naevus flammeus on the skin, venous and lymphatic malformation, excessive growth of soft and bone tissues $[7,8]$. Regarding the late diagnostics patients usually come late in their middle age, after repeated operations on the venous system, when the right and precise diagnostics are not possible as well as the treatment of the disorders of the venous and lymphatic systems, which is documented by the case histories in our workplace. On day 3 after operation she was in good condition and was released from hospital to home care.

\section{References}

1. Klippel M, Trenaunay P (1900) Du naevus variquex osteohypertrophique. Arch. Gen Med Paris 3: 611-672.

2. Mazuch J, Mišánik L, Mitacz K (1988) Syndróm Klippelov. Trenaunayov. Brat LekListy 89: 899-902.

3. Sabol F (2014) Aotic valvae-sparing operation versus Bental and mechanical aortic valvae replacent-midtern results. BratLekListy 115: 292-299.

4. Jankajová M (2008) Má dížka celkového ischemického času (priznaky balon) u pacientov s primarnou PCI dopad na funkciu lavej komory. Kardiologiapreprax17 (2): 15S.

5. Štvrtinová V, Choroby ciev pp. 546-549.

6. Gloviczki P, Driscoll DJ (2007) Klippel-Trenaunay syndrome: current management. Phlebology 22: 291-298.

7. Bliznak J, Staple TW (1974) Radiology of angiodysplasias of the limb. Radiology 110: 35-44.

8. Baskerville PA, Ackroyd JS, Browse NL (1985) The etiology of the KlippelTrenaunay syndrome. Ann Surg 202: 624-627.
Submission Link: https://biomedres.us/submit-manuscript.php

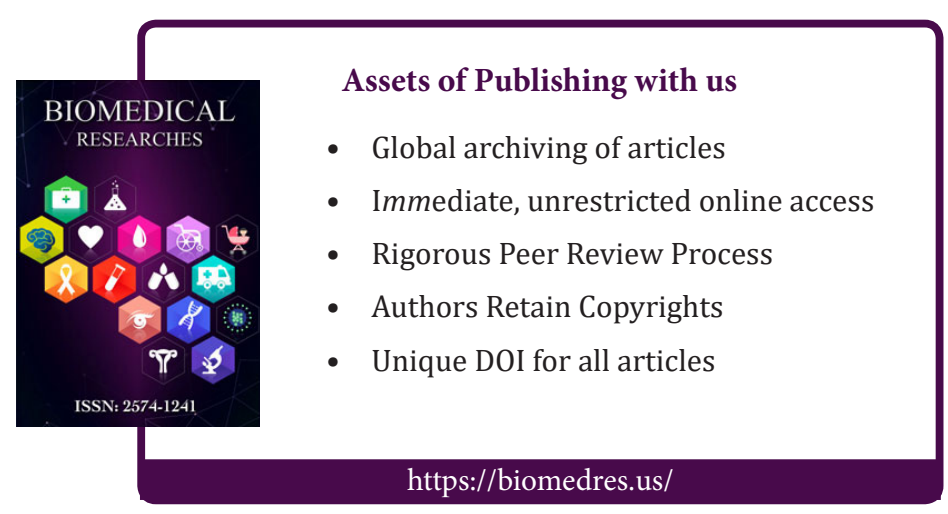

